\title{
Lysophosphatidic acid receptor 2 and Gi/Src pathway mediate cell motility through cyclooxygenase 2 expression in CAOV-3 ovarian cancer cells
}

\author{
Kang Jin Jeong ${ }^{1}$, Soon Young Park', \\ Ji Hye Seo', Kyung Bok Lee', \\ Wahn Soo $\mathrm{Choi}^{2}$, Jeung Whan $\mathrm{Han}^{3}$, \\ Jae Ku Kang ${ }^{1}$, Chang Gyo Park', \\ Yong Kee Kim ${ }^{4}$ and Hoi Young Lee ${ }^{1,5}$ \\ ${ }^{1}$ Myunggok Medical Research Institute \\ College of Medicine, Konyang University \\ Daejeon 302-718, Korea \\ ${ }^{2}$ Department of Immunology and Physiology \\ College of Medicine, Konkuk University \\ Chungju 380-704, Korea \\ ${ }^{3}$ Department of Biochemistry and Molecular Biology \\ College of Pharmacy, Sungkyunkwan University \\ Suwon 440-746, Korea \\ ${ }^{4}$ Department of Pharmacology \\ College of Medicine, Kwandong University \\ Gangneung 210-701, Korea \\ ${ }^{5}$ Corresponding author: Tel, 82-42-600-6413; \\ Fax, 82-42-541-4626; E-mail, hoi@konyang.ac.kr \\ DOI 10.3858/emm.2008.40.6.607
}

Accepted 14 July 2008

Abbreviations: COX, cyclooxygenase; LPA, lysophosphatidic acid; MMP, matrix metalloproteinase; PI3 kinase, phosphatidylinositide 3-kinase; siRNA, small interfering RNA

\begin{abstract}
Lysophosphatidic acid (LPA) is a bioactive phospholipids and involves in various cellular events, including tumor cell migration. In the present study, we investigated LPA receptor and its transactivation to EGFR for cyclooxygenase-2 (COX-2) expression and cell migration in CAOV-3 ovarian cancer cells. LPA induced COX-2 expression in a dose-dependent manner, and pretreatment of the cells with pharmacological inhibitors of Gi (pertussis toxin), Src (PP2), EGF receptor (EGFR) (AG1478), ERK (PD98059) significantly inhibited LPA- induced COX-2 expression. Consistent to these results, transfection of the cells with selective Src siRNA attenuated COX-2 expression by LPA. LPA stimulated CAOV-3 cell migration that was abrogated by pharmacological inhibitors and antibody of EP2.
\end{abstract}

Higher expression of LPA2 mRNA was observed in CAOV-3 cells, and transfection of the cells with a selective LPA2 siRNA significantly inhibited LPA-induced activation of EGFR and ERK, as well as COX-2 expression. Importantly, LPA2 siRNA also blocked LPA-induced ovarian cancer cell migration. Collectively, our results clearly show the significance of LPA2 and Gi/Src pathway for LPA-induced COX-2 expression and cell migration that could be a promising drug target for ovarian cancer cell metastasis.

Keywords: cell movement; cyclooxygenase-2; lysophosphatidic acid; ovarian neoplasms; proto-oncogene proteins pp60 (c-src); receptors, lysophosphatidic acid

\section{Introduction}

Ovarian cancer represents the fourth leading cause of cancer-related death for women in the Western world (Kohn et al., 2003). Main reasons for the low survival rate of patients with ovarian cancer are caused by lack of effective early detection and treatment, as well as the highly metastatic nature of the disease. While most solid tumors metastasize through blood vessels or lymphatic nodes, ovarian cancer metastasizes through direct dissemination from the primary site(s) into the peritoneal cavity (Gardner et al., 1995). The bioactive lipid lysophosphatidic acid (LPA) is detectable in the majority of patients with both early- and late-state ovarian cancer, reaching concentrations of $80 \mu \mathrm{M}$ in both the plasma and ascites of ovarian cancer patients (Xu et al., 1995; Fang et al., 2000). Ovarian cancer cells also produce LPA, thereby maintaining an LPA-rich microenvironment (Fang et al., 2002). Upon binding to $G$ protein coupled plasma membrane receptors (LPA1, LPA2, and LPA3), LPA exerts diverse biological effects, including cell proliferation/survival, induction of neurite retraction, inhibition of gap junctional communication, and stimulation of cell motility (Moolenaar et al., 1997). More recently, LPA4 (GPR23/P2Y9) (Noguchi et al., 2003) and LPA5 (Kotarsky et al., 2006; Lee et al., 2006) have been identified as a subfamily of LPA receptors. They are structurally distinct from other LPA receptors. 
Recent studies on LPA knockout mice indicate that each LPA receptor has distinct function (Contos et al., 2002). Furthermore, LPA1 is widely expressed in human tissues, while the distribution of LPA2 and LPA3 is more restricted (An et al., 1998; Bandoh et al., 1999). Among LPA receptors, LPA2 is aberrantly expressed in various cancer cells, including ovarian cancer cells (Fujita et al., 2003). Therefore, expression of LPA receptor might be closely related to the development of various cancers.

Cyclooxygenase-2 (COX-2) is responsible for the synthesis of PGE2 and other prostaglandins from arachidonic acid (Cao et al., 2002). Expression of COX-2 is elevated in ovarian cancer (Klimp et al., 2001), and LPA promotes aggressive behavior in ovarian cancer cells through induction of COX-2 expression (Symowicz et al., 2005). Despite the importance of COX-2 in LPA-induced invasiveness, the detailed underlying mechanism is remained to be solved. Therefore, we undertook to investigate the role of LPA receptors in LPA- induced COX-2 expression and cell migration and present herein strong evidence that LPA2 and $\mathrm{Gi} / \mathrm{Src}$ transactivation to EGFR are responsible for COX-2 expression and aggressiveness in ovarian cancer cells.

\section{Materials and Methods}

\section{Reagents}

LPA was purchased from Avanti Polar Lipids (Alabaster, $A L)$. Pertussis toxin (Glycerol Solution), AG1478, PD98059, and GM6001 were from Calbiochem (San Diego, CA). VPC32183, AH6809 and AH23848 were from Sigma-Aldrich (St. Louis, MO). Antibodies for LPA2, COX-2, EGFR, phospho-ERK, phospho-Tyr, EP2, c-Src and ERK were from Santa Cruz Biotechnology (Santa Cruz, CA). GAPDH antibody was obtained from Lab Frontier (Seoul, Korea). Enhanced chemiluminescence reagents and Sepharose 4B were from Amersham-Pharmacia Biotech (Piscataway, NJ). LipofectAMINE 2000 was obtained from Invitrogen (Carlsbad, CA). All other reagents used were of the purest grade available.

\section{Cell culture}

CAOV-3, OVCAR-3, PA-1, 2774 and SKOV-3 ovarian cancer cells were purchased from the American Type Culture Collection (Manassas, VA). The cells were maintained in the complete medium that consists of RPMI 1640 (CAOV-3, OVCAR-3, 2774 and SKOV-3) or EMEM (PA-1), supplemented with $10 \%$ FBS in a humidified atmosphere containing
$5 \% \mathrm{CO}_{2}$ at $37^{\circ} \mathrm{C}$. For experimental purposes, the cells $\left(5 \times 10^{5}\right)$ were plated in six-well culture dishes. After 1 day, the cells were serum starved overnight before use.

\section{Reverse transcription-PCR (RT-PCR)}

Total cellular RNA $(1 \mu \mathrm{g})$ isolated from cultured cell line was used for reverse transcription. The cDNA was then subjected to PCR amplification with primer sets for COX-2, LPA1, LPA2, LPA3, and GAPDH: COX-2 forward, 5'-TGGGAAGCCTTCTCTAACCTCTCCT-3'; COX-2 reverse 5'-CTTTGACTGTGGGAGGATACATCTC-3'; LPA1 forward, 5'-TAGTGGTGGTCATTGTGGTCA-3'; LPA1 reverse, 5'GGCAGAGTTGAATTCAGCAAG-3'; LPA2 forward, 5'-TGGCCTACCTCTTCCTCATGTTCC-3'; LPA2 reverse, 5'-ATTGACCAGTGAGTTGGCCT-3'; LPA3 forward, 5'-GTCCATAGCAACCTGACCAAA-3'; LPA3 reverse, 5'-GTTCTCCTGAGAGAAGCAGCA-3', GAPDH forward, 5'-CATCTTCCAGGAGCGAGA-3'; GAPDH reverse, 5'-CTGCTTCACCACCTTCTTGAT-3'. PCR products were analyzed by agarose gel electrophoresis and visualized by treatment with ethidium bromide, and their intensity was compared using EagleSight Software V. 3.2 (Stratagene, La Jolla, CA).

\section{Immunoblotting}

Quiescent cells were treated with $25 \mu \mathrm{M}$ LPA for the indicated period. After solubilizing the cells with $250 \mu$ l of ice-cold buffer (Lee et al., 2005), lysates were resolved by $10 \%$ SDS-PAGE and transferred to PVDF membrane. The membrane was blocked at $4^{\circ} \mathrm{C}$ overnight in a covered container and allowed to react with a specific antibody in 1:1,000 dilution, and detection of specific proteins was carried out by enhanced chemiluminescence following the manufacturer's instruction.

\section{Immunoprecipitation}

Lysates containing $200 \mu \mathrm{g}$ of proteins in extraction buffer were incubated with $4 \mu \mathrm{g} / \mathrm{ml}$ anti-EGFR antibody at room temperature for $5 \mathrm{~h}$. The immunocomplex was precipitated with protein A Sepharose CL-4B beads (Amersham Biosciences, Piscataway) overnight at $4^{\circ} \mathrm{C}$. The beads were washed with PBS containing Tween 20, resuspended in SDS buffer, and boiled for $5 \mathrm{~min}$. The protein samples were then immunoblotted with anti-p-Tyr antibody in 1:1,000 dilution.

\section{Estimation of PGE2 and MMP-2}

The levels of PGE2 and MMP-2 from the con- 
ditioned media of LPA-treated CAOV-3 cells were detected by using the ELISA kits for PGE2 (Cayman Chemical Company, Ann Arbor, MI) and MMP-2 (R\&D Systems, Minneapolis, MN) according to the manufacturer's instructions. To measure the MMP activity, gelatin zymography was utilized as described previously (Lakka et al., 2000). After stimulating with or without LPA for 24 $h$, the cells were washed with PBS and incubated with fresh serum-free medium. After $24 \mathrm{~h}$, conditioned medium was collected and centrifuged, and protein concentrations were determined. Equal amounts of protein were subjected to $0.1 \%$ gelatin SDS-PAGE under nonreducing conditions. Gels were washed in $2.5 \%$ Triton X-100 and incubated

A

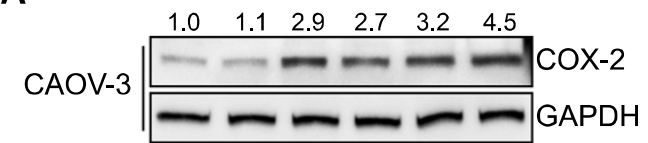

LPA $(25 \mu \mathrm{M}) 0 \mathrm{~h} 1 \mathrm{~h} 3 \mathrm{~h} 6 \mathrm{~h} 12 \mathrm{~h} 24 \mathrm{~h}$

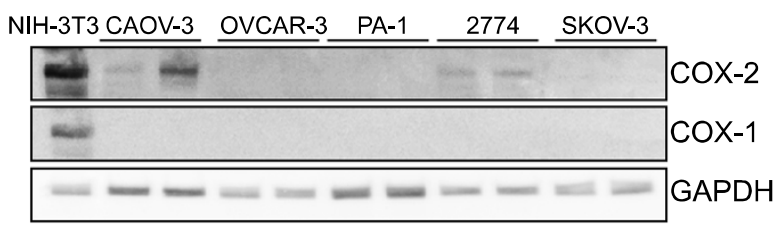

C LPA C LPA C LPA C LPA C LPA
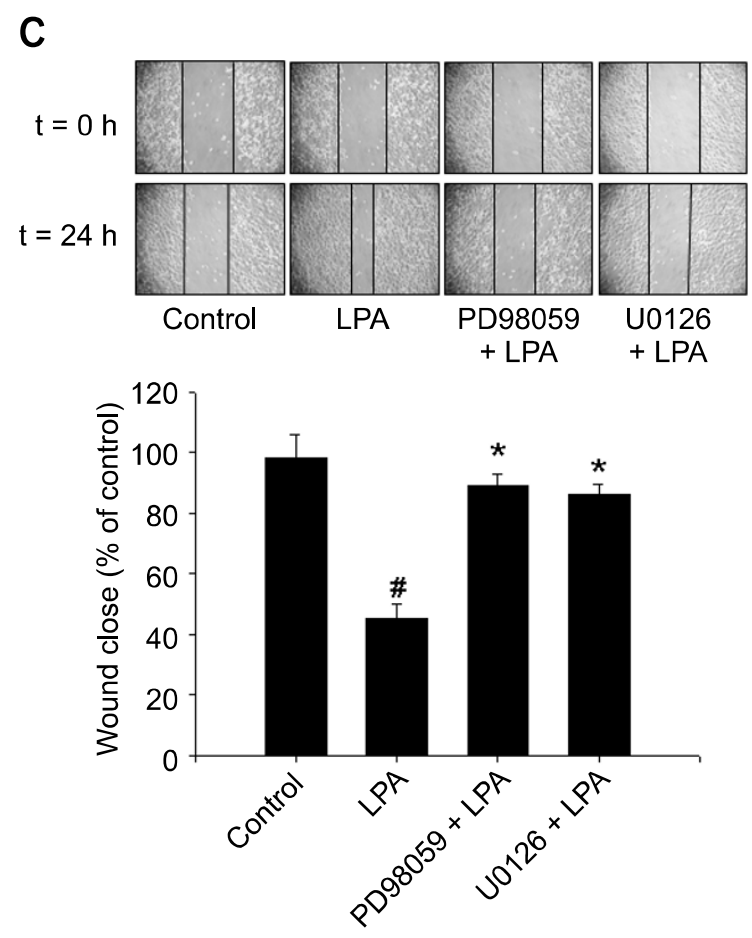

overnight in Tris- $\mathrm{CaCl}_{2}$ buffer. The gels were then stained with $0.5 \%$ Coomassie blue for $1 \mathrm{~h}$ and destained in $20 \%$ methanol and $10 \%$ acetic acid. The clear bands represent gelatinase activity.

\section{Small interfering RNA (siRNA)}

siRNA corresponding to the LPA2 gene was designed and synthesized by Invitrogen life technologies (Carlsbed, CA). The following sequences were used: 5'-UGUGGAACAUGAGGAAGAGGUAGGC-3'. siRNA duplexes were used for transfection at a final concentration of $100 \mathrm{pmol}$. The c-Src siRNA was purchased from Santa Cruz Biotechnology (Santa Cruz, CA) and is a pool of 4

B

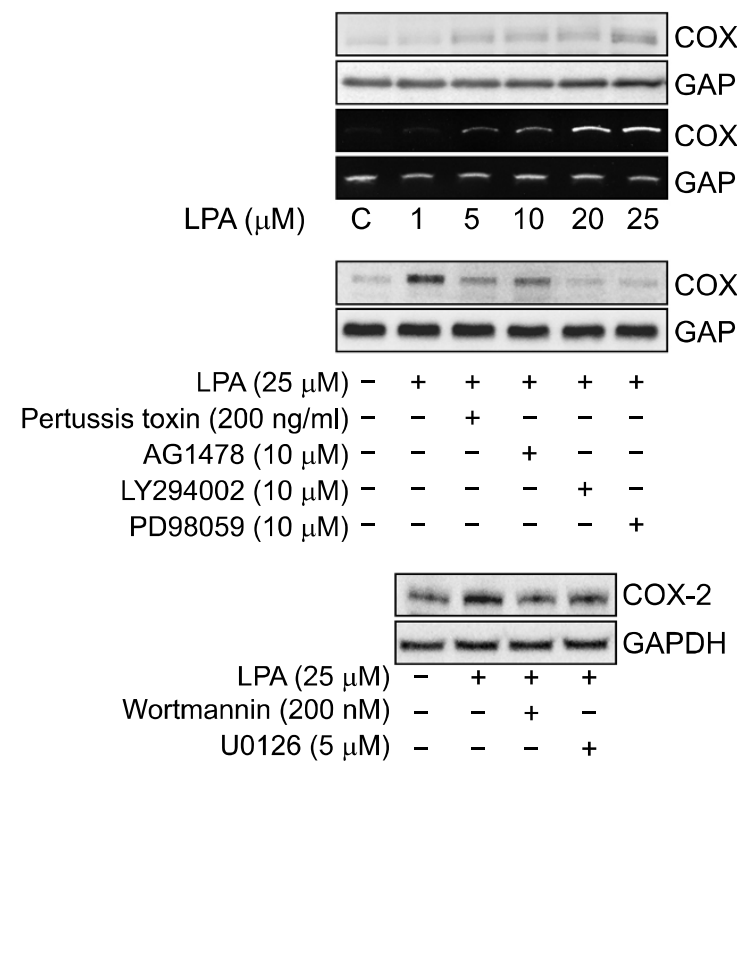

Figure 1. LPA induces COX-2 expression through Gi, EGFR and ERK. (A) The cells were serum starved overnight, and stimulated with LPA for indicated times. Cell lysates were analyzed by immunoblotted against anti-COX-1 or anti-COX-2 antibody. As a control, the lysate of NIH-3T3 cells was analyzed in the same gel. (B) The cells were pretreated with or without pharmacological inhibitors of $\mathrm{Gi}$ (pertussis toxin), $\mathrm{PI} 3$ kinase (LY294002 and wortmannin), EGFR (AG1478), ERK (PD98059 and U0126), followed by stimulation with indicated concentration of LPA. The cell lysates were analyzed by either RT-PCR or immunoblotting. (C) The cells were pretreated with or without indicated pharmacological inhibitors, followed by stimulation with LPA and the cell migration was analyzed at time 0 and $24 \mathrm{~h}$. Results show a representative of three experiments and the mean \pm S.D. of three experiments. ${ }^{\#} P<0.05$ vs. control, ${ }^{*} P<0.05$ vs. LPA treatment. 
target-specific 20-25 nt siRNAs designed to knock down gene expression. Cells were plated onto six-well culture dishes a day before the transfection and then transiently transfected with LipofectAMINE 2000 according to the manufacture's instruction.

\section{Wound healing assay}

The cells were grown to confluence in six-well plates for 2 days and serum starved overnight. A scrape in the form of a cross was made through the confluent monolayer with a plastic pipette tip. The cells were treated with or without inhibitors, followed by LPA treatment. For siRNA experiment, the cells were first transfected with or without siRNA. Then the confluent cells were serum starved overnight, and a scrape was made before LPA treatment. Several wounded areas were marked for orientation, observed, and then photographed by phase contrast microscopy at $24 \mathrm{~h}$ after the scratch.

\section{Statistical analysis}

Results are expressed as the mean \pm S.D. and an analysis was done by one-way Student's t-test. $P$-values less than 0.05 were considered statistically significant.

\section{Results}

\section{LPA induces COX-2 expression}

Ovarian cancer leads to more fatalities than any other form of gynecological cancer in the developed world. As a possible biomarker for ovarian cancer cells, LPA enhances tumor cell motility, proliferation, angiogenesis, survival, invasion and metastasis through LPA receptors (Fang et al., 2000). It has been recently reported that LPA stimulates the expression of COX-2 that promotes aggressive behavior in ovarian cancer DOV13 cells (Symowicz et al., 2005). To determine the effect of LPA on COX-2 expression in our system, the serum-starved various ovarian cancer cells were stimulated by $25 \mu \mathrm{M}$ LPA for $3 \mathrm{~h}$, and COX expression levels were analyzed by immunoblotting (Figure 1A). Among the tested ovarian cancer cells, COX-1 expression was not detectable even in the presence of LPA. While COX-2 was expressed in both CAOV-3 and 2774 cells as the basal level, LPA induced COX-2 expression only in CAOV-3 cells. Furthermore, LPA induced both COX-2 mRNA and protein expression in a dosedependent manner in CAOV-3 cells (Figure 1B).
Next, we treated CAOV-3 cells with various pharmacological inhibitors to determine the intracellular signaling pathway of COX-2 expression by LPA. Induction of COX-2 protein by LPA was completely inhibited by pharmacological inhibitors of phosphatidylinositide 3-kinase (PI3 kinase, LY294002 and wortmannin), ERK (PD98059 and U0126), Gi (pertussis toxin) and EGFR (AG1478), suggesting the critical roles of PI3 kinase ERK, GI and EGFR for COX-2 expression (Figure 1B). To determine the effect of LPA on CAOV-3 cell migration, the cells were stimulated with or without LPA, and the cell migration was measured by wound healing analysis. LPA strongly closed the wound after $24 \mathrm{~h}$ of scratch (Figure 1C). However, LPA-induced cell migration was abrogated when the cells were pretreated with PD98059 or U0126. Therefore, these results clearly show the important role of ERK for LPA-induced cell migration in CAOV-3 cells.

\section{LPA transactivates EGFR through Gi and Src}

Although the role of EGFR for LPA-induced COX-2 expression was previously studied (Symowicz et al., 2005), little is known how EGFR is transactivated by LPA receptor in ovarian cancer cells. To examine EGFR activation by LPA, CAOV-3 cells were treated with pharmacological inhibitors of MMP (GM6001) or Src (PP2), followed by stimulation with LPA. LPA-induced phosphorylation of EGFR and ERK was significantly inhibited by PP2 treatment (Figure 2A). In addition, PP2 treatment also abrogated COX-2 expression by LPA. However, GM6001 treatment did not show any remarkable inhibition of EGFR phosphorylation and COX-2 expression by LPA. These results indicate that Src but not MMP pathway is necessary for LPAinduced EGFR transactivation and COX-2 expression. To confirm the importance of Src on LPAinduced COX-2 expression, the cells were transfected with selective c-Src siRNA, and the expression of COX-2 was analyzed. As shown in Figure 2B, LPA-induced COX-2 expression was profoundly inhibited by C-Src siRNA. Next, CAOV-3 cells were treated with LPA with or without PP2 and GM6001, and MMP-2 expression and activation were monitored to substantiate our data showing COX-2 expression by LPA independent to MMP. As shown in Figure 2C, LPA did not induce the expression and activation of MMP-2.

\section{PGE2 is involved in LPA-induced cell migration}

One of the underlying mechanisms of COX-2 induced cell migration is through the production of 
A

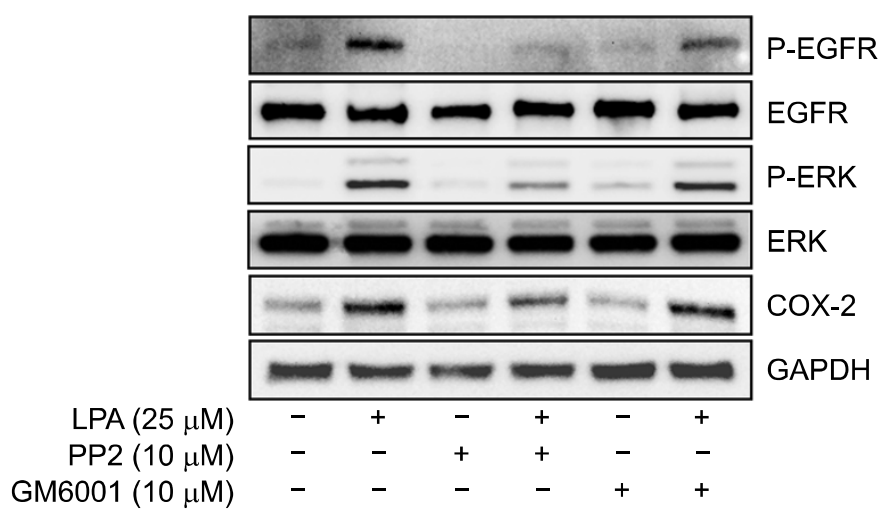

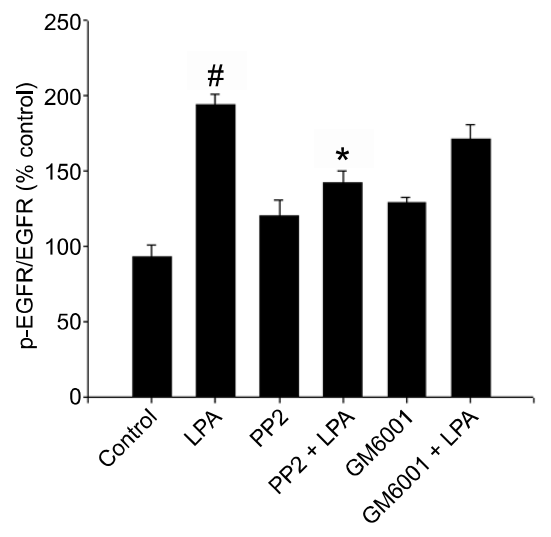

B

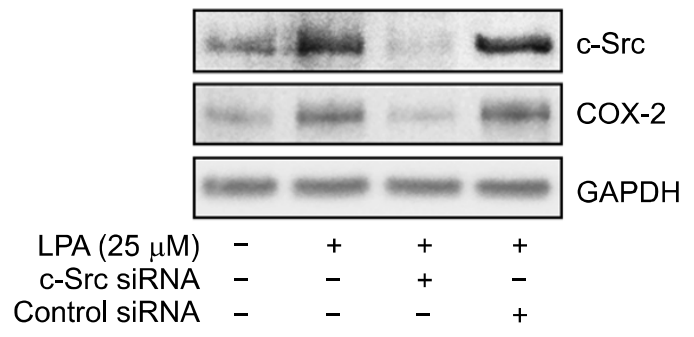

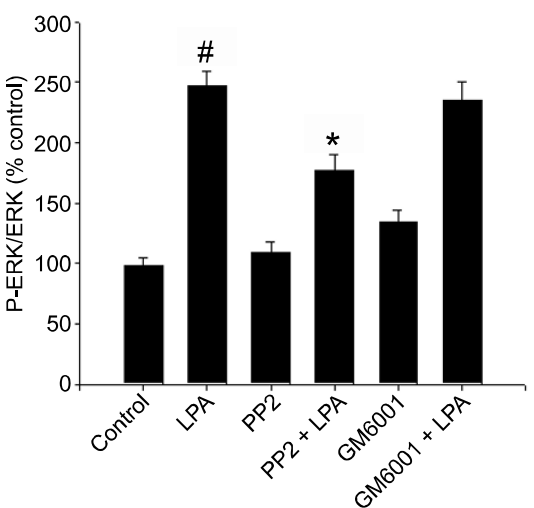

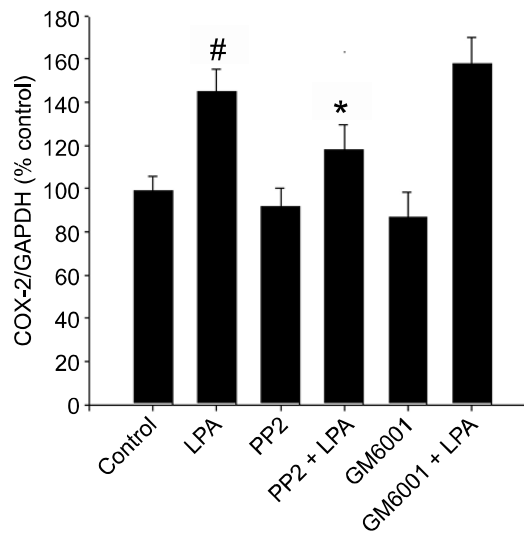

C
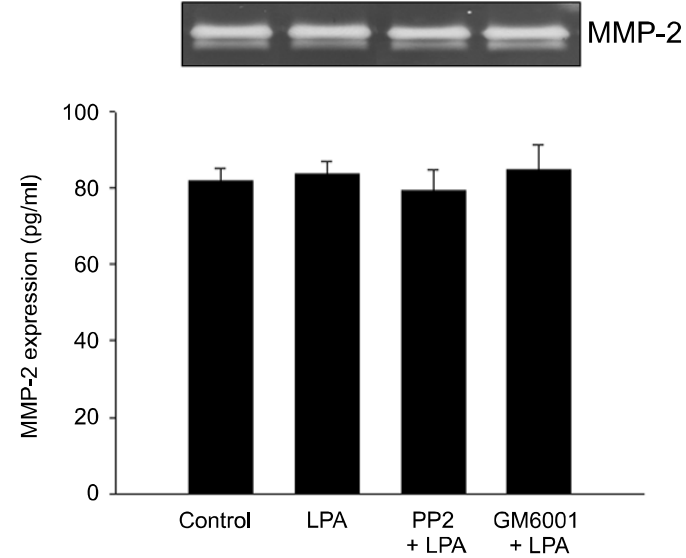

Figure 2. Src is involved in EGFR transactivation. The cells were pretreated with pharmacological inhibitors of Src (PP2) or MMP (GM6001) for $1 \mathrm{~h}$, followed by stimulation with $25 \mu$ M LPA. (A) The cell lysates were immunoblotted as described in materials and methods. Anti-p-Tyr antibody was utilized to detect P-EGFR, after the cell lysate was immunoprecipitated with EGFR antibody. Results show a representative blot of three experiments and the mean \pm S.D. of three experiments. (B) The cells were transfected with either selective c-Src or negative control siRNA, followed by stimulation with or without $25 \mu \mathrm{M}$ LPA. (C) Conditioned media was analyzed by gelatin zymography (upper gel) and ELISA (lower graph) to detect MMP-2 activity and total expression, respectively. Results show a representative gel and ELISA of three experiments. ${ }^{\sharp} P<0.05$ vs. control, ${ }^{*} P<0.05$ vs. LPA treatment.

PGE2, leading to either activation of EGFR (Buchanan et al., 2003) or MAPK/ERK (Krysan et al., 2005). PGE2 also has been implicated in tumorigenesis and tumor progression in several cancers (Eberhart et al., 1994; Kargman et al., 1995; Hida et al., 1998). To test the role of COX-2 
A
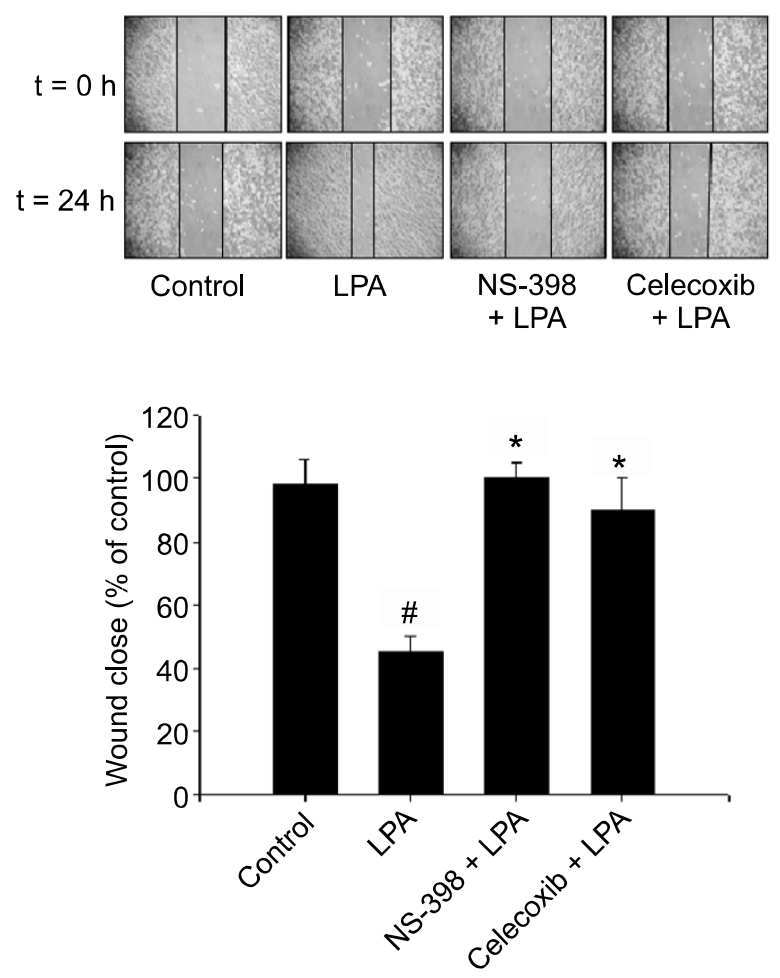

B

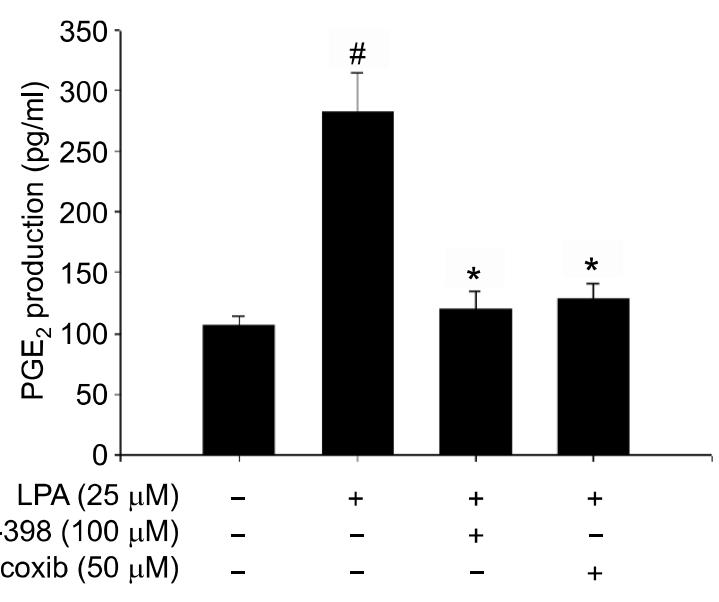

C
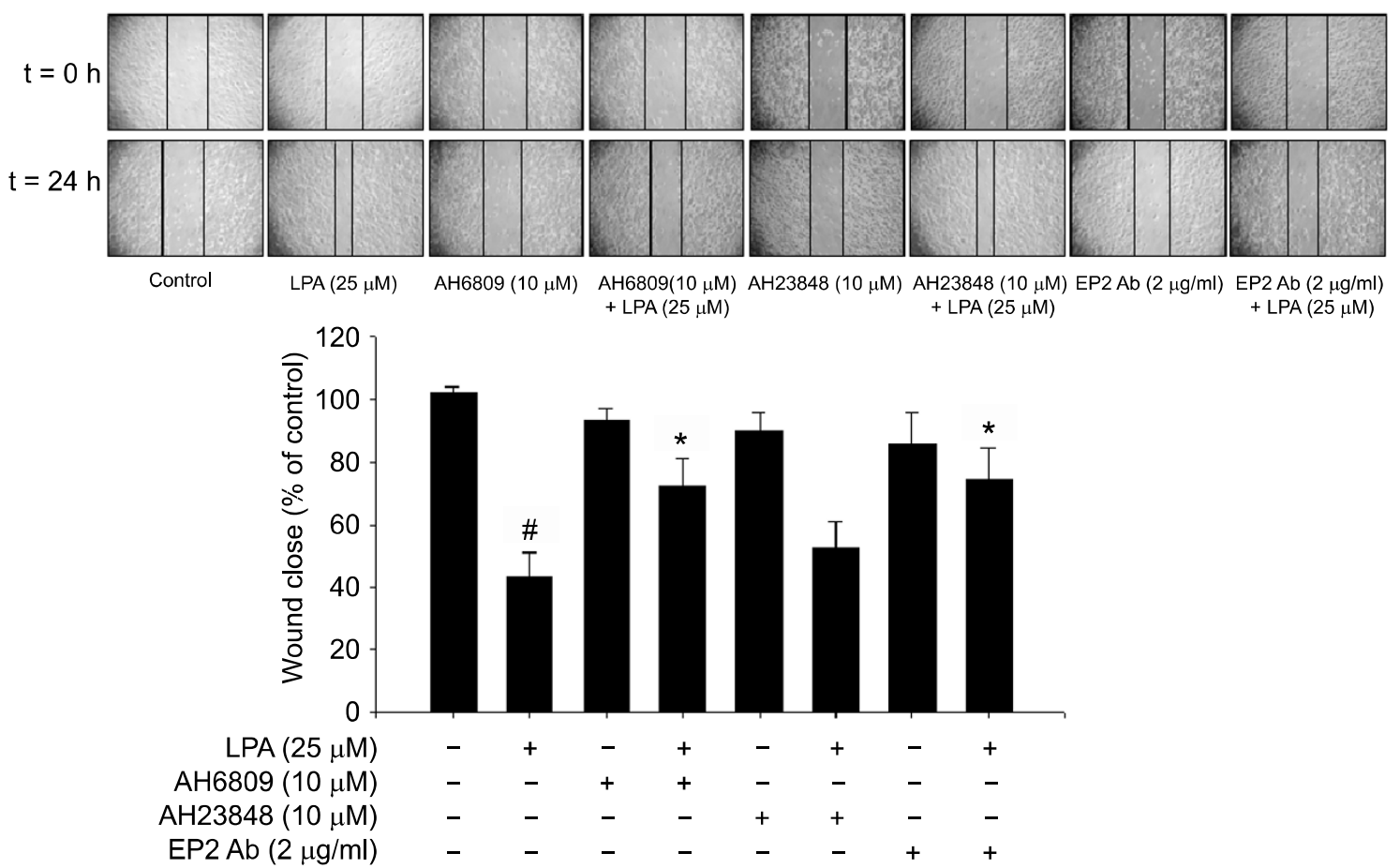

Figure 3. EP2 is involved in LPA-induced cell migration. (A) The cells were pre-incubated with or without pharmacological inhibitors of COX-2 (100 $\mu \mathrm{M}$ NS-398, $50 \mu \mathrm{M}$ celecoxib), followed by $25 \mu \mathrm{M}$ LPA stimulation. The cell migration was assessed by wound healing at time $0 \mathrm{~h}$ and $24 \mathrm{~h}$. (B) Pre-incubated cells with COX-2 inhibitors were stimulated with LPA, and the amount of PGE2 was assessed by ELISA. (C) The cells were pre-incubated with pharmacological inhibitors of EP2 (AH6809), EP4 (AH23848) or anti-EP2 blocking antibody, followed by LPA stimulation. The cell migration was analyzed by wound healing at time $0 \mathrm{~h}$ and $24 \mathrm{~h}$. Results show a representative of five experiments and the mean \pm S.D. of five experiments. ${ }^{\#} P<0.05$ vs. control, ${ }^{*} P<0.05$ vs. LPA treatment. 
on LPA-induced cell migration, the cells were pretreated with COX-2 selective inhibitors. As shown in Figure 3A, LPA-induced cell migration was profoundly inhibited by NS-398 and celecoxib, suggesting the importance of COX-2 for LPA-induced CAOV-3 cell migration. Next, we determined the effect of LPA on PGE2 production. Like other ovarian cancer HEY or OVCAR-433 cells (Spinella et al., 2004), CAOV-3 cells secrete more than 100 $\mathrm{pg} / \mathrm{ml}$ of PGE2 even without any treatment. When the cells were stimulated with LPA, PGE2 secretion was dramatically increased. However, LPA-induced PGE2 production was abrogated in the presence of COX-2 inhibitors (Figure $3 \mathrm{~B}$ ). To gain an insight whether and which receptor of PGE2 is involved in LPA-induced CAOV-3 cell motility, the cells were treated with pharmacological antagonist for EP2 (AH6809) and EP4 (AH23848). As shown in Figure $3 \mathrm{C}$, pretreatment of the cells with AH6809 but not AH23848 significantly inhibited LPA-induced cell migration. Furthermore, treatment of the cells with anti-EP2 antibody profoundly inhibited LPA-induced cell migration. These results suggest the importance of EP2 receptor of PGE2 for CAOV-3 cell migration by LPA.

A

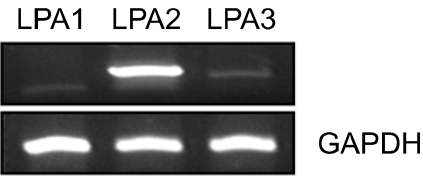

B
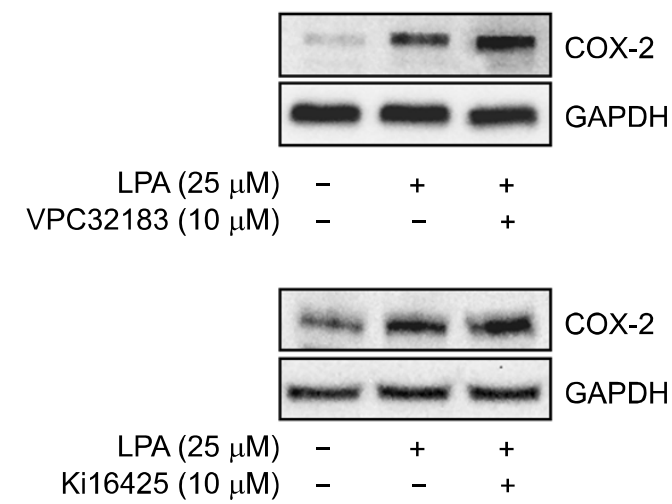

\section{LPA2 is involved in LPA-induced COX-2 expression}

There are at least three types of LPA receptors mediating LPA-induced biological phenomenon, and their differential expression were reported in various cancer cells, including ovarian cancer cells (Wang et al., 2007). To examine the mRNA expression of these LPA receptors in CAOV-3 cells, RT-PCR analysis was utilized with specific LPA receptor primers. As shown in Figure $4 A$, higher mRNA expression of LPA2 was observed compared to that of LPA1 and LPA3. To test which type of receptor is responsible for LPA-induced COX-2 expression, the cells were incubated with VPC32183 or Ki16425 that inhibits LPA1 and LPA3. As shown in Figure 4B, VPC32183 and Ki16425 did not inhibit LPA-induced COX-2 expression, suggesting that LPA1 and LPA3 are not involved in COX-2 expression by LPA. Next, we determined the role of LPA2 on LPA-induced COX-2 expression by utilizing LPA2 specific siRNA. Unlike negative control siRNA, transfection of LPA2 siRNA efficiently reduced the expression of LPA2 protein (Figure 4C), indicating the specificity of LPA2 siRNA. Then, the cells were transfected with LPA2 siRNA, followed by stimulation with LPA. LPA2

C

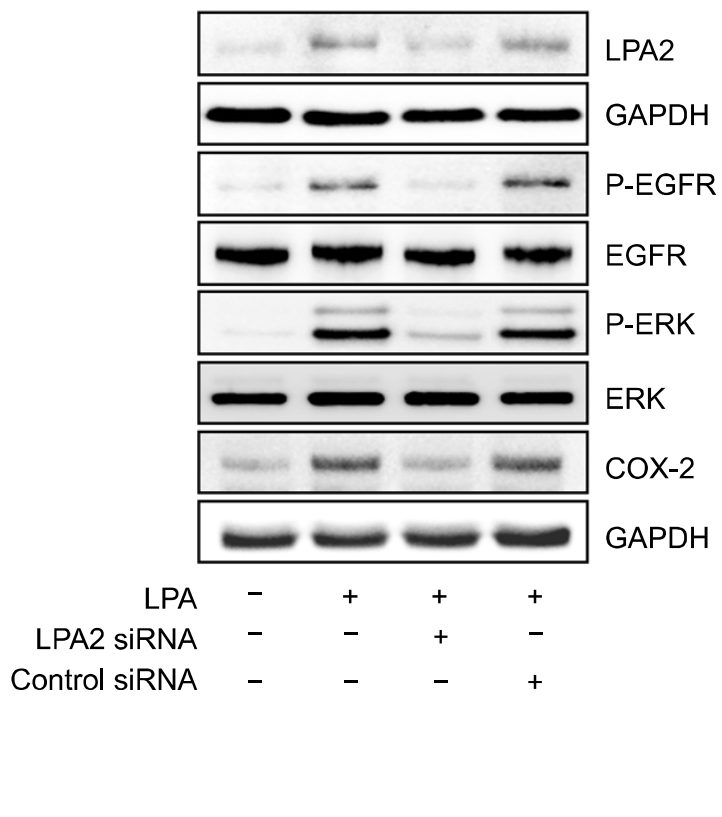

Figure 4. LPA2 is responsible for phosphorylation of EGFR and ERK, as well as COX-2 expression. (A) Total RNA of CAOV-3 cells were reverse transcribed and amplified utilizing specific primers for each LPA receptors with LPA or not as described in Materials and methods. (B) The cells were pretreated with or without pharmacological inhibitors of LPA1 \& LPA3 (VPC32183, Ki16425), followed by stimulation with indicated concentration of LPA. The cell lysates were analyzed by immunoblotting. Results show a representative blot of three experiments. (C) The cells were transfected with either LPA2 specific siRNA or negative control siRNA, followed by stimulation with or without $25 \mu \mathrm{M}$ LPA. The cell lysates were subject to immunoblotting against each antibody. Results show a representative blot of three experiments. 
siRNA completely blocked LPA-induced COX-2 protein expression (Figure $4 \mathrm{C}$ ), suggesting that LPA2 is necessary for COX-2 expression by LPA. Moreover, transfection of the cells with LPA2 siRNA inhibited LPA-induced phosphorylation of EGFR and ERK that are critical for COX-2 expression by LPA. Therefore, these results clearly demonstrate the essential roles of LPA2 on activation of EGFR and ERK, leading to COX-2 expression.

\section{LPA2 is responsible for CAOV-3 cell migration}

LPA receptors are implicated in the cell motility of various types of cells. LPA1 is linked to MC3T3E1 osteoblast motility (Masiello et al., 2006), while LPA2 is involved in RAFTK/PyK2 phosphorylation and PC12 cell motility (Park et al., 2006). Since LPA2 is overexpressed in CAOV-3 cells and involved in COX-2 expression, we tested the role of LPA2 on cell migration. The cells were transfected with either LPA2 specific siRNA or negative control siRNA, followed by stimulation with or without LPA. Transfection of the cells with LPA2 siRNA but not negative control siRNA abrogated
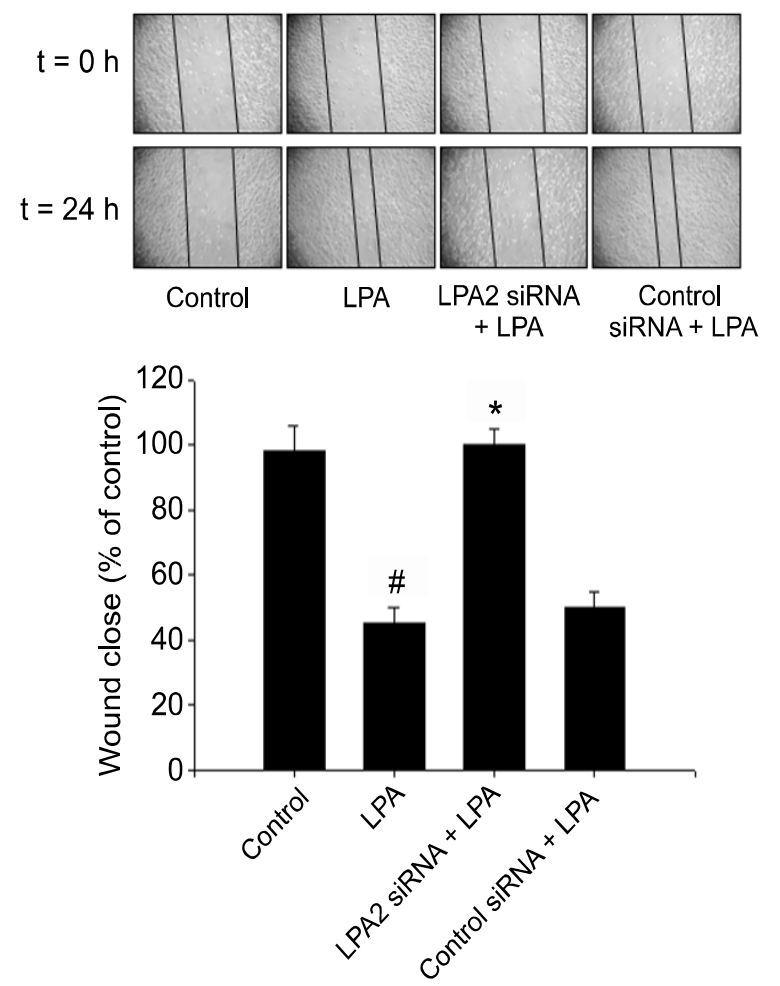

Figure 5. LPA2 is involved in LPA-induced cell motility. The cells were transfected with either LPA2 or negative control siRNA, followed by stimulation with or without $25 \mu \mathrm{M}$ LPA. Results show a representative of four experiments and the mean \pm S.D. of four experiments. ${ }^{\sharp} P<0.05$ vs. control, ${ }^{*} P<0.05$ vs. LPA treatment.
LPA-induced cell migration, indicating the critical role of LPA2 on CAOV-3 cell migration (Figure 5).

\section{Discussion}

Tumor cell invasion and metastasis is a complex, multi-step process during which tumor cells spread from the primary tumor to distant organs (Yang et al., 2006). Accumulated clinical and experimental evidence indicates that COX-2 is involved in the metastatic phenotypes of cancers, including ovarian cancer. In the present study, we for the first time demonstrate the importance of LPA receptor and Gi/Src signaling for LPA-induced EGFR activation, COX-2 expression, as well as motility stimulation in CAOV-3 ovarian cancer cells.

There are several signaling pathways for EGFR transactivation by LPA receptor. One of them involves $\mathrm{Gi}$ and Src. Pretreatment of the adrenal glomerulosa cells with PP2, a Src inhibitor, inhibited EGFR transactivation and ERK activation by LPA (Shah et al., 2005). Another well-known pathway for EGFR transactivation is matrix metalloproteinase (MMP) activation by LPA receptor. MMP stimulates proteolytic cleavage of transmembrane precursors, such as pro-HB-EGF, which subsequently activates the EGFR family (Prenzel et al., 1999; Gschwind et al., 2002). In human bronchial epithelial cells, activation of Lyn and MMP but not Src are required for EGFR transactivation by LPA (Zhao et al., 2006). In the present study, we showed that Src, but not MMP pathway is involved in LPA-induced EGFR activation and COX-2 expression. Pretreatment of the cells with PP2 abolished phosphorylation of EGFR and ERK, as well as COX-2 expression by LPA (Figure 2A). Furthermore, LPA-induced COX-2 expression was also significantly inhibited by Src siRNA pretreatment. Previous report claimed that MMP activation for proteolytic cleavage of transmembrane precursors was a critical step for EGFR activation in human colon cancer cells (Shida et al., 2005). This difference could be due to the types of cancer cells tested.

The relative expression of LPA receptor isotypes depends on the type of cells. While higher expression of LPA-1 was reported in OVCAR-3 cells, LPA3 is the major receptor type in SKOV-3 cells (Park et al., 2007). In the present study, we showed that LPA2 expression is higher than other types of LPA receptor in CAOV-3 cells. These results are in good accord with previous report (Fang et al., 2004). The roles of LPA receptor on cancer cell motility are well documented. LPA1 is required for the motility of breast, prostate, and melanoma 
cells (Hama et al., 2004). Human pancreatic cancer cells also use LPA1 for LPA-induced cell migration (Yamada et al., 2004). However, the LPA receptor responsible for LPA-induced ovarian cancer cell migration is controversial. While LPA2 was reported to mediate LPA-induced human ovarian cancer cell migration (Xu et al., 2004; Symowicz et al., 2005), Sugimoto et al. recently claimed that LPA1 is critical for motility stimulation by LPA in CHO cells (2006). Furthermore, little is known which LPA receptor is responsible for COX-2 expression to stimulate ovarian cancer cell motility. We therefore determined the receptor responsible for LPA-induced COX-2 expression and motility stimulation. Our data clearly demonstrate that LPA2 is critical for COX-2 expression, leading to ovarian cancer cell motility stimulation by LPA. First, much higher expression of LPA2 than LPA1 and LPA3 was shown in CAOV-3 cells. Second, transfection of the cells with LPA2 selective siRNA inhibited phosphorylation of ERK and EGFR, as well as COX-2 expression. Finally and most importantly, transfection of selective LPA2 siRNA abolished motility stimulation by LPA.

In conclusion, our data clearly show that LPA stimulates COX-2 expression and cell motility through LPA2/Gi/Src/EGFR/ERK signaling cascade in ovarian cancer cells. Our results will help to understand the molecular mechanism for LPAinduced motility and useful approach for inhibition of motility in ovarian cancer progression.

\section{Acknowledgments}

This work is supported by the Korea Science and Engineering Fund through the Cancer Metastasis Research Center (CMRC) at Yonsei University (to Lee, HY), a grant from Korea Food and Drug Administration (08172KFDA518, to Lee, HY) and Konyang University Myunggok Medical Research Fund of 2004 (to Park, CG).

\section{References}

An S, Bleu T, Hallmark OG, Goetzl EJ. Characterization of a novel subtype of human $G$ protein-coupled receptor for lysophosphatidic acid. J Biol Chem 1998;273:7906-10

Bandoh K, Aoki J, Hosono H, Kobayashi S, Kobayashi T, Murakami-Murofushi K, Tsujimoto M, Arai $\mathrm{H}$, Inoue $\mathrm{K}$. Molecular cloning and characterization of a novel human G-protein-coupled receptor, EDG7, for lysophosphatidic acid. J Biol Chem 1999;274:27776-85

Buchanan FG, Wang D, Bargiacchi F, DuBois RN. Prostaglandin E2 regulates cell migration via the intracellular activation of the epidermal growth factor receptor. J Biol Chem 2003;278:35451-7
Cao Y, Prescott SM. Many actions of cyclooxygenase-2 in cellular dynamics and in cancer. J Cell Physiol 2002;190: 279-86

Contos JJ, Ishii I, Fukushima N, Kingsbury MA, Ye X, Kawamura S, Brown JH, Chun J. Characterization of Ipa(2) (Edg4) and Ipa(1)//pa(2) (Edg2/Edg4) lysophosphatidic acid receptor knockout mice: signaling deficits without obvious phenotypic abnormality attributable to Ipa(2). Mol Cell Biol 2002;22:6921-9

Eberhart CE, Coffey RJ, Radhika A, Giardiello FM, Ferrenbach S, DuBois RN. Up-regulation of cyclooxygenase 2 gene expression in human colorectal adenomas and adenocarcinomas. Gastroenterology 1994;107:1183-8

Fang X, Gaudette D, Furui T, Mao M, Estrella V, Eder A, Pustilnik T, Sasagawa T, Lapushin R, Yu S, Jaffe RB, Wiener JR, Erickson JR, Mills GB. Lysophospholipid growth factors in the initiation, progression, metastases, and management of ovarian cancer. Ann N Y Acad Sci 2000;905:188-208

Fang X, Schummer M, Mao M, Yu S, Tabassam FH, Swaby $\mathrm{R}$, Hasegawa $\mathrm{Y}$, Tanyi JL, LaPushin R, Eder A, Jaffe R, Erickson J, Mills GB. Lysophosphatidic acid is a bioactive mediator in ovarian cancer. Biochim Biophys Acta 2002;1582:257-64

Fang X, Yu S, Bast RC, Liu S, Xu HJ, Hu SX, LaPushin R, Claret FX, Aggarwal BB, Lu Y, Mills GB. Mechanisms for lysophosphatidic acid-induced cytokine production in ovarian cancer cells. J Biol Chem 2004;279:9653-61

Fujita T, Miyamoto S, Onoyama I, Sonoda K, Mekada E, Nakano H. Expression of lysophosphatidic acid receptors and vascular endothelial growth factor mediating lysophosphatidic acid in the development of human ovarian cancer. Cancer Lett 2003;192:161-9

Gardner MJ, Jones LM, Catterall JB, Turner GA. Expression of cell adhesion molecules on ovarian tumour cell lines and mesothelial cells, in relation to ovarian cancer metastasis. Cancer Lett 1995;91:229-34

Gschwind A, Prenzel N, Ullrich A. Lysophosphatidic acidinduced squamous cell carcinoma cell proliferation and motility involves epidermal growth factor receptor signal transactivation. Cancer Res 2002;62:6329-36

Hama K, Aoki J, Fukaya M, Kishi Y, Sakai T, Suzuki R, Ohta H, Yamori T, Watanabe M, Chun J, Arai H. Lysophosphatidic acid and autotaxin stimulate cell motility of neoplastic and non-neoplastic cells through LPA1. J Biol Chem 2004;279: 17634-9

Hida T, Yatabe Y, Achiwa H, Muramatsu H, Kozaki K, Nakamura S, Ogawa M, Mitsudomi T, Sugiura T, Takahashi T. Increased expression of cyclooxygenase 2 occurs frequently in human lung cancers, specifically in adenocarcinomas. Cancer Res 1998;58:3761-4

Kargman SL, O'Neill GP, Vickers PJ, Evans JF, Mancini JA, Jothy S. Expression of prostaglandin $\mathrm{G} / \mathrm{H}$ synthase-1 and -2 protein in human colon cancer. Cancer Res 1995;55:2556-9

Klimp AH, Hollema H, Kempinga C, van der Zee AG, de Vries EG, Daemen T. Expression of cyclooxygenase-2 and inducible nitric oxide synthase in human ovarian tumors and tumor-associated macrophages. Cancer Res 2001;61: 


\section{$7305-9$}

Kohn EC, Mills GB, Liotta L. Promising directions for the diagnosis and management of gynecological cancers. Int $\mathrm{J}$ Gynaecol Obstet 83 Suppl 2003;1:203-9

Kotarsky K, Boketoft A, Bristulf J, Nilsson NE, Norberg A, Hansson S, Owman C, Sillard R, Leeb-Lundberg LM, Olde B. Lysophosphatidic acid binds to and activates GPR92, a G protein-coupled receptor highly expressed in gastrointestinal lymphocytes. J Pharmcol Expe Ther 2006;318: 619-28

Krysan K, Reckamp KL, Dalwadi H, Sharma S, Rozengurt E, Dohadwala M, Dubinett SM. Prostaglandin E2 activates mitogen-activated protein kinase/Erk pathway signaling and cell proliferation in non-small cell lung cancer cells in an epidermal growth factor receptor-independent manner. Cancer Res 2005;65:6275-81

Lakka SS, Jasti SL, Kyritsis AP, Yung WK, Ali-Osman F, Nicolson GL, Rao JS. Regulation of MMP-9 (type IV collagenase) production and invasiveness in glioma by the extracellular signal-regulated kinase and jun amino-terminal kinase signaling cascades. Clin Exp Metastasis 2000;18: 245-52

Lee CW, Rivera R, Gardell S, Dubin AE, Chun J. GPR92 as a new G12/13- and Gq-coupled lysophosphatidic acid receptor that increases cAMP, LPA5. J Biol Chem 2006; 281:23589-97

Lee J, Jung ID, Chang WK, Park CG, Cho DY, Shin EY, Seo DW, Kim YK, Lee HW, Han JW, Lee HY. p85 beta-PIX is required for cell motility through phosphorylations of focal adhesion kinase and p38 MAP kinase. Exp Cell Res 2005; 307:315-28

Masiello LM, Fotos JS, Galileo DS, Karin NJ. Lysophosphatidic acid induces chemotaxis in MC3T3-E1 osteoblastic cells. Bone 2006;39:72-82

Moolenaar WH, Kranenburg O, Postma FR, Zondag GC. Lysophosphatidic acid: G-protein signalling and cellular responses. Curr Opin Cell Biol 1997;9:168-73

Noguchi K, Ishii S, Shimizu T. Identification of p2y9/GPR23 as a novel $G$ protein-coupled receptor for lysophosphatidic acid, structurally distant from the Edg family. J Biol Chem 2003;278:25600-6

Park KS, Lee HY, Lee SY, Kim MK, Kim SD, Kim JM, Yun J, Im DS, Bae YS. Lysophosphatidylethanolamine stimulates chemotactic migration and cellular invation in SK-OV3 human ovarian cancer cells: involvement of pertussis toxin-sensitive G-protein coupled receptor. FEBS Lett 2007;581:4411-6

Park SY, Schinkmann KA, Avraham S. RAFTK/Pyk2 mediates LPA-induced PC12 cell migration. Cell Signal 2006;18:1063-71

Prenzel N, Zwick E, Daub H, Leserer M, Abraham R, Wallasch $C$, Ullrich A. EGF receptor transactivation by
G-protein-coupled receptors requires metalloproteinase cleavage of proHB-EGF. Nature 1999;402:884-8

Shah BH, Baukal AJ, Shah FB, Catt KJ. Mechanisms of extracellularly regulated kinases $1 / 2$ activation in adrenal glomerulosa cells by lysophosphatidic acid and epidermal growth factor. Mol Endocrinol 2005;19:2535-48

Shida D, Kitayama J, Yamaguchi H, Yamashita H, Mori K, Watanabe T, Nagawa H. Lysophosphatidic acid transactivates both c-Met and epidermal growth factor receptor, and induces cyclooxygenase-2 expression in human colon cancer LoVo cells. World J Gastroenterol 2005;11:5638-43

Spinella F, Rosano L, Di Castro V, Natali PG, Bagnato A. Endothelin-1-induced prostaglandin E2-EP2, EP4 signaling regulates vascular endothelial growth factor production and ovarian carcinoma cell invasion. J Biol Chem 2004;279: 46700-6

Sugimoto N, Takuwa N, Yoshioka K, Takuwa Y. Rhodependent, Rho kinase-independent inhibitory regulation of Rac and cell migration by LPA1 receptor in Gi-inactivated CHO cells. Exp Cell Res 2006;312:1899-908

Symowicz J, Adley BP, Woo MM, Auersperg N, Hudson LG, Stack MS. Cyclooxygenase-2 functions as a downstream mediator of lysophosphatidic acid to promote aggressive behavior in ovarian carcinoma cells. Cancer Res 2005; $65: 2234-42$

Wang P, Wu X, Chen W, Liu J, Wang X. The lysophosphatidic acid (LPA) receptors their expression and significance in epithelial ovarian neoplasms. Gynecol Oncol 2007;104: 714-20

Xu J, Lai YJ, Lin WC, Lin FT. TRIP6 enhances lysophosphatidic acid-induced cell migration by interacting with the lysophosphatidic acid 2 receptor. J Biol Chem 2004;279: 10459-68

Xu Y, Gaudette DC, Boynton JD, Frankel A, Fang XJ, Sharma A, Hurteau J, Casey G, Goodbody A, Mellors A, et al. Characterization of an ovarian cancer activating factor in ascites from ovarian cancer patients. Clin Cancer Res 1995;1:1223-32

Yamada T, Sato K, Komachi M, Malchinkhuu E, Tobo M, Kimura T, Kuwabara A, Yanagita Y, Ikeya T, Tanahashi Y, Ogawa T, Ohwada S, Morishita Y, Ohta H, Im DS, Tamoto K, Tomura H, Okajima F. Lysophosphatidic acid (LPA) in malignant ascites stimulates motility of human pancreatic cancer cells through LPA1. J Biol Chem 2004;279: 6595-605

Yang J, Mani SA, Weinberg RA. Exploring a new twist on tumor metastasis. Cancer Res 2006;66:4549-52

Zhao Y, He D, Saatian B, Watkins T, Spannhake EW, Pyne NJ, Natarajan V. Regulation of lysophosphatidic acidinduced epidermal growth factor receptor transactivation and interleukin-8 secretion in human bronchial epithelial cells by protein kinase Cdelta, Lyn kinase, and matrix metalloproteinases. J Biol Chem 2006;281:19501-11 